$\mathbb{T}$ periodica polytechnica

Civil Engineering

$52 / 2(2008) 57 \quad 62$

doi: 10.3311/pp.ci.2008-2.01

web: http://www.pp.bme.hu/ci

(c) Periodica Polytechnica 2008

RESEARCH ARTICLE

\section{The reiterative accuracy of gait determined by simplified gait analysis}

Rita M. Kiss

Received 2008-06-04, accepted 2008-08-27

\section{Abstract}

Dynamic perception is the perception of the relation of moving body parts to each other. To examine dynamic perception, the reiterative accuracy of well-known movements - for example, gait - is analysed. Simplified gait analysis can be obtained for 50 cycles of gait in this research. The high number of gait cycles analysed provides an opportunity to calculate the average and standard deviation of different temporal (duration of stance phase, swing phase, double support phase) and spatial parameters (step length, stride length, cadence) of each subject investigated. 45 healthy, young subjects, 11 professional hand ball players, 24 patients after medial meniscectomy, 20 elderly, healthy subjects, and 20 patients with hip osteoarthritis are investigated. The average, standard deviation and normalized deviation of parameters of each person are calculated. The normalized deviation of parameters enables modelling of dynamic perception, because it is independent from the value of parameters due to normalization. Our tests show that the size of the parameter is independent from lateral dominance at healthy subjects. The size of the normalized deviation of parameters depends on age, on the intensity of sports activities, and on orthopaedical diseases.

\section{Keywords}

gait analysis $\cdot$ dynamic perception $\cdot$ normalized deviation

\section{Acknowledgement}

This work was supported in part by the Hungarian Scientific Fund T049471. Special thanks to Professor Kocsis for his advice and help. Special thanks to Árpád Illyés MD PhD, Mátyás Magyar MD, Zsolt Knoll MD PhD and Zoltán Bejek MD for their help in the completion of measurements.

\section{Rita M. Kiss}

Department of Structures, University of Pécs, 7624 Pécs, Boszorkány utca 2., Hungary

e-mail: kissrit@t-online.hu

\section{Introduction}

Proprioception refers to the perception of the position of and motion by the upper and lower limbs and the trunk. Stimuli from the trunk and hip play a primordial role in assisting the correction of human balance, while proprioceptive stimuli from the lower limb mainly determine posture, intermuscular coordination, and gait [5, 9]. Thus, proprioception (static perception) is the perception of the relation of moving body parts to each other in repose [1]. To examine proprioception, the reiterative accuracy of a certain setting of a static position trained earlier is analysed. This means that the subject is requested to place the joint being examined in a certain spatial position, for example, $90^{\circ}$ flexion (bending), in such a way that he/she may only rely on stimuli from superficial and deep feelings, without any visual stimuli. Most studies on joint proprioception have been performed on anterior cruciate-deficient knees [4, 6, 10]. Recently, there has been an increasing number of reports on the measurement of proprioception in knees after arthroplasty [3, 5, 12] or in the hip [11, 13, 15]. However, the measurement method used in these studies is complicated and requires precise cooperation from the patient examined. Furthermore, perception during continuous motion cannot be studied by this method.

The evaluation of gait parameters during walking is helpful in assessing abnormal gait, in quantifying improvements resulting from intervention, or in predicting subsequent events such as ageing or falls. Since ultrasound-based measuring and recording techniques were developed, gait analysis has been frequently used in almost all fields of human locomotion [18]. An ultrasound-based measuring system is used for functional performance assessment after treatment or surgery such as anterior ligament reconstruction surgery [20], meniscectomy [21], hip [17] and knee arthoplasty [7]. The system is useful for analysing the effects of osteoarthrithis [8] and sports [19].

The simplified gait analysis determined the kinetic parameters and the temporal, spatial gait parameters from the ground reaction force in function of time during constant speed gait on an instrumented treadmill. Verification studies suggest that the method is reliable [16]. Simplified gait analysis can be obtained not only for few gait cycles but also for a number of gait cycles. 
Dynamic perception is the perception of the relation of moving body parts to each other. To examine dynamic perception, the reiterative accuracy of well-known movements is analysed. Simplified gait analysis can be obtained for a number of gait cycles, and the motion of the upper and lower limbs does not hide the markers, the motion is more comfortable. So my hypothesis is that simplified gait analysis can be used to determine the deviation of temporal and spatial parameters observed during gait cycles. The goal of this research is to determine and compare the deviation of spatial and temporal gait parameters at different healthy subjects, such as young, older and professional athletes, and at patients after meniscectomy and with hip osteoarthritis.

\section{Subject and method}

\subsection{Subjects}

The population studied consists of the following groups:

1 healthy young subjects (45 persons)

2 healthy young professional hand ball players (11 persons)

3 healthy elderly subjects (20 persons)

4 young subjects after meniscectomy (24 persons)

5 elderly subjects with hip osteoarthritis (20 persons).

The anthropometrical data of the subjects investigated are summarized in Table 1 Subjects in healthy groups are without any clinical history of diseases or injuries in the lower extremities. Patients after meniscectomy had bucket-handle tear in the posterior medial part of the meniscus. The excited proportion of the meniscus was less than $30 \%$. We did not find ligament injuries, concomitant chondral lesions and signs of osteoarthritis. The time form injury to surgery was less than three months in case of all patients. The symptoms of osteoarthritis were negative in all cases at the time of gait analysis as well. Gait analysis was performed 18 months after surgery. The average Harris Hip Score of patients with unilateral coxarthritis was 51.3 points $( \pm$ 15.2), all patients had poor results (HHS $<70$ points). All patients were seriously limited in their activities due to the pain.

The tests were authorized by the Science and Research Ethics Committee of Semmelweis University. Each voluntary subject provided an informed written consent to performing the tests in advance.

\subsection{Methods}

The basic system consists of an instrumented treadmill ergometer (Kistler) with two built-in force plates; the treading area of 1500x500 mm has more than 5000 high-quality capacitive pressure/force sensors (Fig. 1). The instrument and the PC are linked via a USB interface. The zebris WINFDM-T measuring program collects the vertical components of the ground reaction force during gait. The measurement frequency is $1000 \mathrm{~Hz}$. Using a technology specially developed by ZEBRIS, the movement of the treadmill is compensated so that completely stable

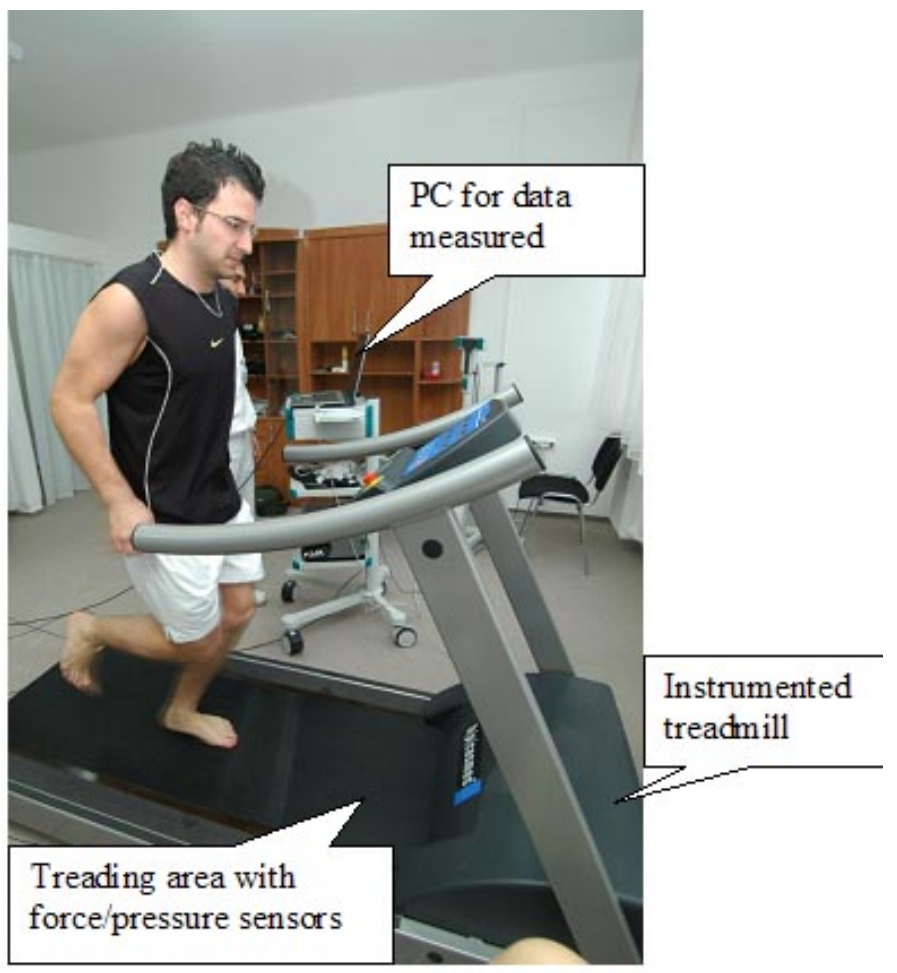

Fig. 1. Instruments of simplified gait analysis

gait and roll-off patterns can be analysed. The measurements are performed at the Biomechanical Laboratory of the Hospital of Hungarian Railways in Szolnok and at the Biomechanical Laboratory of the Department of Applied Mechanics at Budapest University of Technology and Economics.

The subjects, in everyday clothes without shoes, walked on a motorized treadmill (Fig. 1). The treadmill was set at $2.5 \mathrm{~km} / \mathrm{h}$ constant speed. Walking on the treadmill can initially be an unfamiliar experience. This in turn can influence the parameters measured. Therefore, the measurement starts after six minutes of familiarization time as suggested by Alton et al [2] and Matsas et al [22]. The measuring program collected the vertical components of the ground reaction force during at least fifty gait cycles (Fig.2).

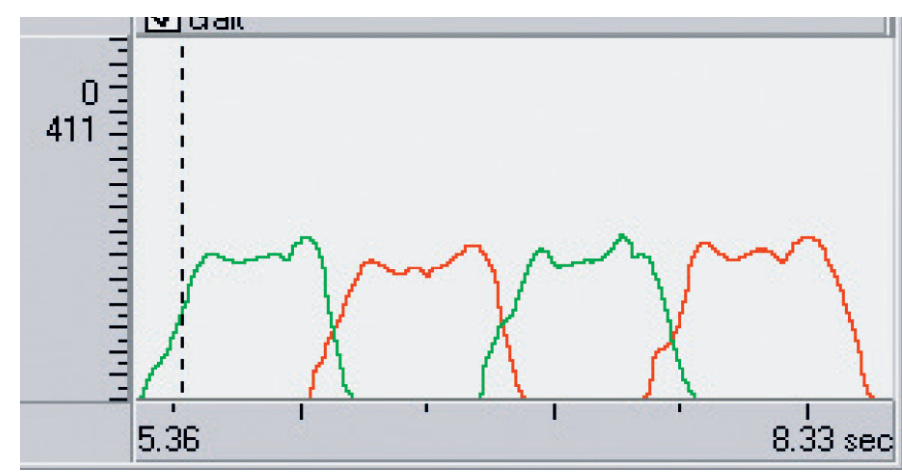

Fig. 2. Temporal parameters calculated from the graph of ground reaction force vs. time 
Tab. 1. Anthropometrical data of investigated subjects

\begin{tabular}{lllll}
\hline Group & Number & Age & Height & Weight \\
\hline & male/female & years & $\mathrm{cm}$ & $\mathrm{kg}$ \\
Healthy young & $23 / 22$ & $24.17 \pm 9.09$ & $169.42 \pm 3.11$ & $68.12 \pm 15.88$ \\
Hand ball players & $11 / 0$ & $24.47 \pm 4.09$ & $181.42 \pm 13.09$ & $84.73 . \pm 8.88$ \\
Healthy elderly & $8 / 12$ & $68.82 \pm 9.18$ & $169.13 \pm 19.55$ & $73.36 \pm 11.43$ \\
Subjects after meninscectomy & $13 / 11$ & $29.55 \pm 4.72$ & $168.76 \pm 9.82$ & $70.31 \pm 9.97$ \\
Elderly with hip osteoarthritis & $8 / 12$ & $69.75 \pm 8.91$ & $172.56 \pm 11.34$ & $70.16 \pm 9.17$ \\
\hline
\end{tabular}

\subsection{Assessment parameters}

The temporal parameters calculated from the ground reaction force in function of time (Fig. 2) are as follows:

- length of stance phase (stance time) $\left[t_{\text {stance }}-\mathrm{s}\right]$

- length of swing phase (swing time) $\left[t_{\text {swing }}-\mathrm{s}\right]$

- length of double support phase $\left[t_{d o u b l e}-\mathrm{s}\right]$

- time of step $\left[t_{\text {step }}-\mathrm{s}\right]$

The spatial parameters calculated from temporal parameters and constant gait speed $\left[v_{\text {gait }}-\mathrm{m} / \mathrm{s}\right]$ are as follows [16]:

- cadence [c - step/minutes]

- step length $\left[l_{\text {step }}-\mathrm{mm}\right]$

- stride length

For each subject, the average and standard deviation of the temporal and spatial parameters were determined from 50 complete gait cycles. A disadvantage of applying the standard deviation of individuals' parameters for modelling dynamic perception is that it depends on the value of parameters. Results of various subjects cannot be compared to proper accuracy. In order to eliminate the error, the standard deviation of individuals was normalized by the average value. The normalized deviation of individuals does not depend on the value of parameters, it represents the deviation of motion of the subject investigated, which, in turn, models dynamic perception. These data were further processed. In the further process the average and standard deviation of groups were calculated from the average and standard deviation of parameters of individuals.

All variable differences were tested for normal distribution using the Kolmogorov-Smirnov test. All variable differences showed normal distribution, the overall comparison of gait patterns between the groups was made by ANOVA. Statistical significance was set at $\mathrm{p}<0.05$.

\section{Results}

For the sake of clarity, the results are summarized in Tables 2 . 4 in average \pm SD form. All subjects were able to walk 50 gait cycles on the treadmill at a speed of $2.5 \mathrm{~km} / \mathrm{h}$.

The average of individuals' spatial and temporal parameters (Table 2) are not analysed here as they have already been published in detail [8, 17, 21]. In summary, we can establish that the spatial and temporal parameters depend on age, sports, and the different orthopaedical diseases.

The deviation of individuals' spatial and temporal parameters can be considerably affected by the parameters' average value, therefore data evaluation is not objective (Table 3). The normalized deviation introduced in order to eliminate differences is independent from the parameters' average value (Table 4). On the basis of our results we can establish the following:

1 Normalized deviation in healthy young subjects is 0.18 . There were no significant differences between comparing values of the dominant and non-dominant side $(p=0.24)$ and the values of different parameters $(p=0.29)$.

2 Normalized deviation in hand ball players is 0.14 . There were no significant differences between comparing values of the dominant and non-dominant side $(p=0.37)$ and the values of different parameters $(p=0.33)$. It is significantly smaller ( $p=0.004)$ than the normalized deviation of healthy young subjects.

3 Normalized deviation in subjects after meniscectomy is 0.20 on the non-affected side and 0.26 on the affected side. There were no significant differences between comparing the values of different parameters $(p=0.15)$. The normalized deviation of the non-affected side is significantly smaller $(p=0.0009)$ than that of the affected side. The normalized deviation of both sides at patients is significantly ( $p=0.0006)$ higher than that of healthy young subjects.

4 Normalized deviation in healthy, elderly subjects is 0.23 . There were no significant differences between comparing the values of the dominant and non-dominant side $(p=0.24)$ and the values of different parameters $(p=0.25)$. It is significantly higher ( $p=0.0002)$ than the normalized deviation of healthy young subjects.

5 Normalized deviation in subjects with hip osteoarthritis is 0.27 on the non-affected side and 0.35 on the affected side. There were no significant differences between the values of different parameters $(p=0.19)$. The normalized deviation of the non-affected side is significantly smaller $(p=0.0003)$ than that of the affected side. The normalized deviation of both sides at patients is significantly ( $p=0.0002)$ higher than that of healthy elderly subjects. 
Tab. 2. Average $\pm \mathrm{SD}$ of average of individuals' spatial-temporal parameters

\begin{tabular}{|c|c|c|c|c|c|c|}
\hline \multirow[t]{4}{*}{ Group } & \multicolumn{2}{|c|}{ Length of swing phase } & \multirow{4}{*}{$\begin{array}{l}\text { Length of double } \\
\text { support phase } \\
\% \text { of cycle }\end{array}$} & \multirow{4}{*}{$\begin{array}{l}\text { Cadence } \\
\text { step/minutes }\end{array}$} & \multicolumn{2}{|c|}{ Step length } \\
\hline & \multicolumn{2}{|c|}{$\%$ of cycle } & & & \multicolumn{2}{|c|}{$\mathrm{mm}$} \\
\hline & Dominant/ & Non-dominant/ & & & Dominant/ & Non-dominant/ \\
\hline & Healthy & Affected & & & Healthy & Affected \\
\hline Healthy young & $44.34 \pm 3.11$ & $40.23 \pm 2.99$ & $12.44 \pm 3.01$ & $59.59 \pm 12.45$ & $613.12 \pm 26.6$ & $611.34 \pm 23.3$ \\
\hline Hand ball players & $39.86 \pm 2.14$ & $38.98 \pm 2.67$ & $8.67 \pm 2.12$ & $51.34 \pm 7.84$ & $655.56 \pm 12.34$ & $649.98 \pm 14.56$ \\
\hline Healthy elderly & $32.34 \pm 3.74$ & $31.57 \pm 3.12$ & $21.51 \pm 1.79$ & $89.64 \pm 7.86$ & $497.85 \pm 37.35$ & $496.92 \pm 37.93$ \\
\hline \multicolumn{7}{|l|}{ Subjects after } \\
\hline meninscectomy & $43.93 \pm 2.58$ & $38.86 \pm 4.97$ & $11.47 \pm 3.43$ & $65.42 \pm 18.35$ & $563.25 \pm 32.05$ & $539.92 \pm 12.70$ \\
\hline \multicolumn{7}{|l|}{ Elderly with hip } \\
\hline osteoarthritis & $32.6 \pm 3.1$ & $31.4 \pm 3.4$ & $19.1 \pm 1.8$ & $105.8 \pm 9.1$ & $389.1 \pm 32.3$ & $358.9 \pm 32.3$ \\
\hline
\end{tabular}

Tab. 3. Average $\pm \mathrm{SD}$ of average of deviation of individuals' spatial-temporal parameters

\begin{tabular}{|c|c|c|c|c|c|c|}
\hline \multirow[t]{3}{*}{ Group } & \multicolumn{2}{|c|}{ Length of swing phase } & \multirow{3}{*}{$\begin{array}{l}\text { Length of double } \\
\text { support phase } \\
\% \text { of cycle }\end{array}$} & \multirow{3}{*}{$\begin{array}{l}\text { Cadence } \\
\text { step/minutes }\end{array}$} & \multicolumn{2}{|c|}{ Step length } \\
\hline & \multicolumn{2}{|c|}{$\%$ of cycle } & & & \multicolumn{2}{|c|}{$\mathrm{mm}$} \\
\hline & $\begin{array}{l}\text { Dominant/ } \\
\text { Healthy }\end{array}$ & $\begin{array}{l}\text { Non-dominant/ } \\
\text { Affected }\end{array}$ & & & $\begin{array}{l}\text { Dominant/ } \\
\text { Healthy }\end{array}$ & $\begin{array}{l}\text { Non-dominant/ } \\
\text { Affected }\end{array}$ \\
\hline Healthy young & $7.98 \pm 0.05$ & $7.24 \pm 0.03$ & $2.23 \pm 0.02$ & $10.72 \pm 0.09$ & $110.35 \pm 0.35$ & $110.04 \pm 0.34$ \\
\hline Hand ball players & $5.58 \pm 0.02$ & $5.45 \pm 0.03$ & $1.21 \pm 0.02$ & $7.19 \pm 0.07$ & $91.74 \pm 0.28$ & $90.99 \pm 0.25$ \\
\hline Healthy elderly & $7.47 \pm 0.06$ & $7.24 \pm 0.05$ & $4.94 \pm 0.03$ & $20.61 \pm 0.13$ & $114.49 \pm 0.43$ & $114.29 \pm 0.44$ \\
\hline Subjects after meninscectomy & $7.86 \pm 0.08$ & $10.03 \pm 0.10$ & $2.98 \pm 0.04$ & $17.01 \pm 0.19$ & $112.65 \pm 0.55$ & $140.37 \pm 0.63$ \\
\hline Elderly with hip osteoarthritis & $8.82 \pm 0.10$ & $10.99 \pm 0.14$ & $6.68 \pm 0.03$ & $37.03 \pm 0.21$ & $105.06 \pm 0.46$ & $125.65 \pm 0.58$ \\
\hline
\end{tabular}

Tab. 4. Average \pm SD of normalized deviation of individuals' spatial-temporal parameters

\begin{tabular}{|c|c|c|c|c|c|c|}
\hline \multirow[t]{3}{*}{ Group } & \multicolumn{2}{|c|}{ Length of swing phase } & \multirow{3}{*}{$\begin{array}{l}\text { Length of double } \\
\text { support phase } \\
\% \text { of cycle }\end{array}$} & \multirow{3}{*}{$\begin{array}{l}\text { Cadence } \\
\text { step/minutes }\end{array}$} & \multicolumn{2}{|c|}{ Step length } \\
\hline & \multicolumn{2}{|c|}{$\%$ of cycle } & & & \multicolumn{2}{|c|}{$m m$} \\
\hline & $\begin{array}{l}\text { Dominant/ } \\
\text { Healthy }\end{array}$ & $\begin{array}{l}\text { Non-dominant/ } \\
\text { Affected }\end{array}$ & & & $\begin{array}{l}\text { Dominant/ } \\
\text { Healthy }\end{array}$ & $\begin{array}{l}\text { Non-dominant/ } \\
\text { Affected }\end{array}$ \\
\hline Healthy young & $0.183 \pm 0.004$ & $0.182 \pm 0.005$ & $0.184 \pm 0.003$ & $0.181 \pm 0.007$ & $0.183 \pm 0.002$ & $0.182 \pm 0.003$ \\
\hline Hand ball players & $0.144 \pm 0.001$ & $0.143 \pm 0.003$ & $0.142 \pm 0.002$ & $0.139 \pm 0.003$ & $0.142 \pm 0.001$ & $0.142 \pm 0.004$ \\
\hline Healthy elderly & $0.234 \pm 0.003$ & $0.233 \pm 0.002$ & $0.233 \pm 0.004$ & $0.232 \pm 0.005$ & $0.232 \pm 0.004$ & $0.238 \pm 0.002$ \\
\hline $\begin{array}{l}\text { Subjects after } \\
\text { meninscectomy }\end{array}$ & $0.201 \pm 0.005$ & $0.263 \pm 0.006$ & $0.261 \pm 0.003$ & $0.263 \pm 0.006$ & $0.204 \pm 0.003$ & $0.264 \pm 0.005$ \\
\hline $\begin{array}{l}\text { Elderly with hip } \\
\text { osteoarthritis }\end{array}$ & $0.273 \pm 0.002$ & $0.347 \pm 0.003$ & $0.346 \pm 0.005$ & $0.349 \pm 0.004$ & $0.271 \pm 0.005$ & $0.351 \pm 0.006$ \\
\hline
\end{tabular}




\section{Discussion}

Dynamic perception is the perception of the relation of moving body parts to each other. To examine dynamic perception, the reiterative accuracy of gait is analysed in this research. Simplified gait analysis can be obtained for 50 cycles of gait in this research. The high number of gait cycles analysed gives us the opportunity to calculate the average and standard deviation of different temporal and spatial parameters of each subject investigated.

The normalized deviation of parameters enables the modelling of dynamic perception, because it is independent from the value of parameters due to normalization. Our tests show that the size of the parameter is independent from lateral dominance at healthy subjects (Table 4). On the basis of our tests, it was established that there was no significant difference between the average values of temporal and spatial parameters at healthy subjects (Table 2), either, what also proves the independence of the normalized deviation of parameters from lateral dominance.

The normalized deviation of parameters does not depend on the type of parameters, because dynamic perception is independent from the type of modelling parameters. It means that the analysis of one or few parameters is enough for modelling dynamic perception.

The value of normalized deviation of professional athletes is significantly smaller than that of healthy age-matched nonprofessional athletes (Table 4). This confirms the assumption that sports develop static [14] and dynamic perception [14].

The value of normalized deviation of healthy elderly subjects is significantly higher than that of healthy young persons (Table 47. This confirms the assumption that proprioception declines with age [9].

The value of normalized deviation of patients after meninscectomy at both sides is higher than that of healthy agematched persons (Table 4). This means that the dynamic perception of the non-affected side declines after the surgery. The value of normalized deviation of the affected side is higher than that of the non-affected healthy side (Table 4). This confirms the assumption of Mc Nicolson [23]. He assumes that the reduced spatial-temporal parameters and decreased range of knee motion are caused by worse dynamic perception [23]. This finding correlates with the fact that the injury of anterior cruciate ligaments reduce proprioception [4,6, 10$]$.

The value of normalized deviation of patients with coxarthrosis at both sides is higher than that of healthy age-matched persons (Table 4). This means that the dynamic perception of the non-affected side declines. The value of normalized deviation of the affected side is higher than that of the non-affected healthy side (Table 4). This finding correlates with the fact that coxarthirtis reduces static proprioception [9]11].

In conclusion, the simplified gait analysis method can be used for describing the spatial and temporal parameters of a number of gait cycles. The average and standard deviation of parameters of each subject investigated can be calculated. The normalized deviation of parameters enables the modelling of dynamic perception, because it is independent from the value of parameters due to normalization. Our tests show that the size of the parameter is independent from lateral dominance at healthy subjects. The size of the normalized deviation of parameters depends on age, on the intensity of sports activities, and on orthopaedical diseases. The deviation of spatial and temporal parameters during gait cycles provide a useful, simple quantitative evaluation of the effect of age, movement deficits or sport activities on dynamic perception and movement stability.

\section{References}

1 Allum JHJ, Bloem BR, Carpenter MG, Hulliger M, Hadders-Algra M, Proprioceptive control of posture: a review of new concepts, Gait Posture 8 (1998), 214-242, DOI 10.1016/S0966-6362(98)00027-7.

2 Alton F, Baldey L, Caplan S, Morrissey MC, A kinematic comparison of over ground and treadmill walking, ClinBiomech 13 (1988), 434-440.

3 Attfield SF, Wilton TJ, Pratt DJ, Sambatakakis A, Soft tissue balance and recovery of proprioception after total knee replacement, $\mathrm{J}$ Bone Joint Surg 78B (1996), 540-545.

4 Barrack RL, Skinner HB, Buckley SL, Proprioception in the anterior cruciate deficient knee 17 (1989), 1-6.

5 Barrett DS, Cobb AG, Bentley G, Joint proprioception in normal, osteoarthritic and replaced knees, J Bone Joint Surg BR 73B (1991), 53-56.

6 Barrett DS, Proprioception and function after anterior cruciate reconstruction, J Bone Joint Surg 73B (1991), 833-837.

7 Bejek Z, Illyés Á, Paróczai R, Kiss RM, Kinematics of knee replacement in patients during gait, Proceeding of the $4^{\text {th }}$ IASTED International Conference on Biomechanics BioMech 2006 Palma de Mallorca, 2006, pp. 77-80.

8 Bejek Z, Paróczai R, Illyés Á, Kiss RM, The influence of walking speed on gait parameters in healthy people and in patients with osteoarthritis, Knee Surgery Sports Traumatology Arthroscopy 4 (2006), 612-622, DOI 10.1007/s00167-005-0005-6.

9 Duncan PW, Chandler J, Studenski S, Hughes M, Prescott B, How do physical components of balance affectHow do physical components of balance affect mobility in elderly men?, Arch Phys Med Rehabil 74 (1993), 1343-1349.

10 Good L, Beynnon BD, Gottlieb DJ, Renström PA, Johnson RJ, Joint position sense is not changed after ACL disruption, Trans Orthop Res Soc 20 (1995), 95.

11 Grigg P, Finermann GA, Riley LH, Joint position sense after total hip replacement, J Bone Joint Surg 55A (1973), 1016-1025.

12 Ishii Y, Terajami K, Terashima S, Bechtold JE, Laskin RS, Comparison of joint position sense after total knee replacement, J Arthoplasty 12 (1997), 541-545, DOI 10.1016/S0883-5403(97)90177-7.

13 Ishii Y, Tojo T, Terajima K, Terashima S, Bechtold JE, Intracapsular components do not change hip proprioception, J Bone Joint Surg 81B (1999), 345-348, DOI 10.1302/0301-620X.81B2.9104.

14 Jákó P, Martos É, Pucsok J, A sportorvoslás alapjai, Print City Kiadó, 1998.

15 Karanjina PN, Ferguson $\mathbf{J H}$, Passive joint position sense after total hip replacement surgery, Ann Neurol 13 (1983), 654-657, DOI 10.1002/ana.410130612.

16 Kiss RM, Kocsis L, Verification of simpilified gait analysis, Periodica Polytechnica Ser. Civ. Eng. (under publication).

17 Kiss RM, Illyés Á, Comparison of gait parameters in patients with total hip arthroplasty following direct lateral and antero lateral surgical approach, 
Proceedings of the $6^{\text {th }}$ IASTED International Conference on Biomedical Engineering BioMED 2008 Innsbruck, 2008, pp. 113-120.

18 Kiss RM, Kocsis L, Knoll Zs, Joint kinematics and spatial temporal parameters of gait measured by an ultrasound based system, Medical Engineering \&Physics 26 (2004), 611-620, DOI 10.1016/j.medengphy.2004.04.002.

19 Knoll Zs, Kiss RM, Gait pattern of professional fencers, FACTA UNIVERSITATIS Series Physical Education (University of Nis) 1 (2003), 33-41.

20 Knoll Zs, Kiss RM, Kocsis L, Gait adaptation in ACL deficient patients before and after anterior cruciate ligament reconstruction surgery, Journal of Electromyography and Kinesiology 14 (2004), 287-297, DOI 10.1016/j.jelekin.2003.12.005.

21 Magyar OM, Illyés Á, Knoll Zs, Kiss RM, Effect of medial meniscectomy on gait parameters, Knee Surgery Sports Traumatology Arthroscopy 16 (2008), 427-433, DOI 0.1007/s00167-007-0430-9.

22 Matsas A, Taylor N, McBurney H, Knee joint kinematics from familiarized treadmill walking can be generalized to over ground walking in young unimpaired subjects, Gait and Posture 11 (2000), 46-53.

23 McNicholas MJ, Gibbs S, Linskell JR, Barker S, McGurty D, Rowley DI, The influence of external knee moments on the outcome of total meniscectomy. A comparison of radiological and 3D gait analysis measurements., Gait and Posture 11 (2000), 233-238, DOI 10.1016/S0966-6362(00)00050-3. 